\title{
O MANUAL DIDÁTICO PROJETO ARARIBÁ HISTÓRIA NO MUNICÍPIO DE CAMPO GRANDE, MS (2008)
}

\author{
Carla Villamaina Centeno1 \\ Universidade Estadual de Mato Grosso do Sul- UEMS \\ carla.centeno@uol.com.br
}

\section{RESUMO:}

O presente trabalho expõe resultados parciais de uma pesquisa realizada com manuais didáticos de História do Brasil. Nesse estudo, analisamos o manual didático Projeto Araribá História, adotado em todas as escolas da Rede Municipal de Campo Grande- MS, no ano de 2008. A análise objetiva, por um lado, evidenciar as características dos conteúdos veiculados pelo manual didático e, por outro, apreender as funções por ele assumidas na relação educativa. Para aprofundar a análise dos conteúdos, procuramos apreender a interpretação da Guerra da Tríplice Aliança(1864-1870). Decorrem da análise algumas conclusões: 1) Foi dada pouca atenção à Guerra da Tríplice Aliança, limitando-se a discuti-la em uma página de conteúdo. 2) Quanto à interpretação utilizada, os autores usam do ecletismo metodológico; 3) Do ponto de vista do trabalho didático, observa-se a simplificação dos conteúdos; 4) O manual apresenta seções que prometem trabalhar com fontes históricas diversas, mas há predominância de textos elaborados pelos próprios autores; 5) No Guia do Professor são disponibilizadas textos para ampliar e complementar os conteúdos bem como sugestões de leituras e de filmes, mas esses são acessórios ao trabalho didático.

Palavras-chave: História da Educação, manual didático, História do Brasil, Guerra da Tríplice Aliança.

\section{THE EDUCATIONAL MANUAL PROJETO ARARIBÁ HISTÓRIA IN THE MUNICIPALITY OF CAMPO GRANDE, MS (2008)}

\begin{abstract}
:
The present article shows partial results of a research done with textbooks of Brazil History. In this study, we have analysed the textbook Projeto Araribá História, adopted in all schools of Municipal Network of Campo Grande - MS, in the year of 2008. The analysis aims, on the one side, to evidence the characteristics of the contents conduced by the textbook and, on the other side, to apprehend the functions assumed by it in the educative relation. To deepen the analysis of the contests, we have tried to perceive the interpretation of the Triple Alliance War (1864 - 1870). Some conclusions result from the analysis: 1) It was given little attention to the Triple Alliance War, it was discussed in a page of content. 2) Related to the interpretation used, the authors use the methodological eclecticism, 3) From the point of view of the educational work, we can realize the simplification of the contests; 4) The textbook presents sections that promise to work with different historical sources, but there is predominance of texts elaborated by the authors themselves. 5) In the Teacher's Guide texts are available to enlarge and to complement the contents as well as suggestions of readings and films, but these are accessories to the educational work.

Keywords: History of education, textbook, history of Brazil, Triple Alliance War
\end{abstract}




\section{Introdução}

O presente artigo expõe resultados parciais de um estudo realizado com manuais didáticos de História do Brasil. Este estudo está vinculado a um Programa de Pesquisa que elege como objeto de investigação os instrumentos do trabalho didático em diversas áreas de conhecimento2

O Projeto Araribá foi o manual de História que mais teve aceitação entre os professores da rede municipal de ensino em Campo Grande3. Dentre as 82 escolas municipais que participaram do processo de escolha do Programa Nacional do Livro Didático, 56 optaram pelo referido manual. Daí ter sido adotado em todas as escolas da REME no ano de 2008.

No Guia do Programa Nacional do Livro Didático (PNLD) de 2008, o Projeto Araribá História conquistou o segundo lugar na avaliação, só perdendo para História em projetos, da Editora Ática, que recebeu nota máxima em todos os quesitos.

Trata-se, pois, de analisar um instrumento que ganhou destaque não somente em Campo Grande, Mato Grosso do Sul, mas entre profissionais da área que prestam consultoria ao MEC.

Tendo em vista esses dados, a análise objetiva, por um lado, evidenciar as características dos conteúdos veiculados pelo manual didático e, por outro, apreender as funções por ele assumidas na relação educativa. Quanto aos conteúdos, optou-se pela seleção de uma temática específica, no caso a Guerra da Tríplice Aliança (1864-1870), evento que, a par de sua relevância histórica para Mato Grosso do Sul e para o Brasil, sempre alimentou controvérsias.

\section{O manual didático enquanto instrumento central do ensino básico}

O pressuposto inicial é o de que qualquer abordagem acerca do trabalho didático, tal como se realiza em sala de aula, envolvendo os procedimentos pedagógicos do professor, o conteúdo didático selecionado e, sobretudo, o instrumental utilizado, objeto desse trabalho, impõe um recuo aos primórdios da escola moderna. Esse recuo é necessário porque torna inteligíveis as bases em que a escola contemporânea está assentada e alguns dos problemas postos na área especializada do ensino de História.

O manual, segundo Alves (2006), é o instrumento que impõe certo grau de objetivação ao trabalho didático e, na mesma medida, estabelece o domínio sobre as operações realizadas pelo professor em sala de aula. Segundo Alves (2006) o manual didático é um instrumento que preserva características manufatureiras.

A escola de nosso tempo, organizada por níveis de ensino e seriação dos estudos, teve origem no século XVII com Comenius, pastor protestante nascido na Morávia. É o que afirma Alves

Comenius está na origem da escola moderna. A ele, mais do que a nenhum outro, coube o mérito de concebê-la. Nessa empreitada, foi impregnado pela clareza de que o estabelecimento escolar deveria ser pensado como uma oficina de homens (Alves, 2006, p. 71).

Comenius concebeu uma instituição social especializada, a escola moderna, cuja finalidade era "ensinar tudo a todos". Esta instituição deveria inserir a divisão do trabalho na escola tal como já acontecia nas manufaturas. Para ele, o estabelecimento escolar deveria ser pensado como uma oficina de homens, ou seja, como uma manufatura. De fato, Comenius viajara por toda a Europa e conhecia a discussão sobre a ciência moderna e os avanços na produção de mercadorias decorrente da instauração da divisão manufatureira do trabalho. 
Tomando como modelo o trabalho produtivo, para ele, era possível e necessário implantar a divisão do trabalho na escola, tal como se dera na manufatura, gerando mais resultados, com economia de tempo, de fadiga e de recursos. Para Alves (2006, p. 75) a preocupação de Comenius com os determinantes materiais tem passado despercebida aos historiadores que analisam sua obra. Comenius tinha consciência, segundo o autor, das dificuldades econômicas para implantar a escola para todos. A proposta comeniana visava ao barateamento da escola, pois a queda de custos era condição primordial à sua universalização (ALVES, 2006, p. 74-75). Mas, à sua época, existiam impedimentos desde a falta de educadores conhecedores do método, bem como de instrumental para realizar o trabalho didático nos novos moldes.

O remédio para essa dificuldade, segundo o pastor protestante, deveria ser buscado, prioritariamente, na transformação do instrumental do trabalho didático. Para Comenius, somente com a produção e inserção de instrumentos que expusessem todos os conteúdos e orientassem o trabalho didático era possível viabilizar a escola para todos. Denominados por ele de "livros pan-methódicos", os manuais didáticos seriam os instrumentos mais importantes da máquina escolar.

O manual possibilitaria a queda de custos, pois realizava certo grau de simplificação e de objetivação do trabalho didático. Com a revolução no instrumental, expressa no surgimento do manual didático, qualquer homem de capacidade intelectual mediana poderia ensinar. Para que a escola se universalizasse era necessário, então, transformar o preceptor em trabalhador especializado, retirar-lhe em grande parte o domínio teórico-prático do trabalho que realizava. O próprio Comenius apontou que esse novo profissional, o professor, dado o seu grau de especialização, não poderia formular os conteúdos expostos nos manuais. Para Comenius ninguém deveria retirar "da própria cabeça" o que ensinar e como ensinar (COMENIUS, 1997, p. 363) Os professores ministrariam suas aulas com uma instrução "já preparada" (id,ibd, 1997, p. 363). Para isso, era necessária a contratação de um novo tipo de trabalhador especializado: o compendiador, recrutado entre homens eruditos, "ricos de engenho" (id,ibd, 1997, p. 373). Comenius também sugere a necessidade de especializar essa modalidade de trabalho. Para ele, seria impossível a designação dessa empreitada a "um só homem, sobretudo se estiver ocupado com outros afazeres ou não souber exatamente tudo o que é necessário para um método universal" (id,ibd, p. 373). Mas essa especialização era limitada à época de Comenius, pois conduzida por uma espécie de corporação, uma "sociedade colegiada". (id. ibd., 1997, p. 373) Estes homens, os compendiadores, passariam a selecionar e resumir os conteúdos, que, materializados nos manuais didáticos, norteariam o trabalho em sala de aula.

Comenius prescreveria, ainda, aos educadores

[...] normas precisas às quais conformem seu trabalho; isso significa que, para seu uso, é preciso escrever livros informativos que indiquem de que modo e quando eles devem agir para não errar. Portanto, os livros didáticos serão de dois tipos: os relativos às coisas (reais) para os estudantes e os informativos para os professores, para que estes sejam capazes de usar os primeiros com rapidez e perfeição (COMENIUS, 1997, p. 365).

O manual didático deveria resumir um programa de conteúdos informativos, dispôlos em ordem seqüencial e condicionar os procedimentos docentes necessários ao seu uso. Enfim, dar a tônica ao trabalho didático. Nesse sentido, Comenius eliminou qualquer possibilidade de uso de livros clássicos e apontou, até mesmo, para o caráter dispensável do próprio mestre: "[...] acima de tudo, desejo e solicito que os assuntos sejam expostos em linguagem familiar e comum, para permitir que os alunos entendam tudo espontaneamente, mesmo sem mestre" (id. ibid, p. 217, grifos nossos). 
As matérias seriam ensinadas uma de cada vez com um método único (id.ibid., 1997, p. 219) e com livros "de tamanho pequeno mas de grande utilidade, que apresentem as coisas sumariamente, ou seja, muitas coisas com poucas palavras (id.ibid, 1997, p.221). Esse método deveria privilegiar as coisas para, num momento posterior, relacioná-las às palavras: "por que, então, a instrução deveria começar pela explicação verbal das coisas e não por sua observação direta? Só depois que o objeto foi mostrado é que pode ser explicado melhor com palavras" (id.ibid, 1997, p. 233). Mas, se não fosse possível se dispor das coisas seria necessário utilizar imagens que as representassem, "feitas especialmente para o ensino" (id.ibid, 1997, p. 235). E em Comenius acha-se uma regra fundamental da nova ordem nascente: atribuir aos conteúdos uma utilidade: "tudo que se ensina deve ser ensinado como coisa atual e de inquestionável utilidade" (id,ibid, 1997, p. 238). Nada deveria ser ensinado que não tivesse uso imediato (id.,ibid, 1997, p. 181).

Na prática, no Brasil, a adoção dos instrumentos de trabalho propostos pela escola comeniana tem suas primeiras objetivações no século XIX, mas limitados ainda aos colégios secundários. Os primeiros manuais de História Universal, segundo Guy de Hollanda (1957, p. 104), eram importados da França. Foi o caso, por exemplo, de Histoire de La Civilization, manual de Ch. Seignobos, adotado nas escolas secundárias que seguiam o modelo dos programas do Colégio Pedro II (HOLLANDA, 1957, p. 104). Os manuais brasileiros foram produzidos, em sua maior parte, pelos professores do Colégio Pedro II, a exemplo dos de Joaquim Manoel de Macedo, Luiz de Queirós Mattoso Maia. Esses professores não eram somente os responsáveis pela fixação dos programas, mas, frequientemente, participavam do Instituto Histórico e Geográfico do Brasil, daí comungarem, este e o Colégio Pedro II, "o mesmo arcabouço conceitual e problematização" do conhecimento histórico (ABUD, 1998, p. 30).

$\mathrm{Na}$ área de história foi muito difundido, no último terço do século XIX, o manual Lições de História do Brasil, de Joaquim Manuel de Macedo, "obra adoptada pelo Conselho Superior da Instrucção publica para uso das escolas de ensino primário" (MACEDO, 1905, folha de rosto). Esse manual desenvolvia a lição e trazia também as explicações a ela referentes, para orientar o professor. Em seguida, vinham o quadro sinótico e as perguntas para resumir e orientar a memorização do conteúdo pelo aluno (MACEDO, 1905, p. 1).

A partir da década de 1930 os manuais escritos em língua estrangeira foram proibidos. Entre os compêndios mais utilizados, até a década de 1940, destacavam-se Epítome de História Universal, de Jonathas Serrano, e História Universal, de João Ribeiro (HOLLANDA, 1957, p. 108-10). Desde o início do século, outro manual de João Ribeiro, História do Brasil, tornara-se muito difundido.

Mas, a maior parte desses manuais não era expressão de domínio sobre a atividade do professor. Foram incorporados ao trabalho didático como instrumentos auxiliares do docente. Apesar de terem substituído e simplificado os compêndios escolares do século XIX, tais manuais ainda eram complexos, desenvolviam os conteúdos por meio de longos textos e, sobretudo, eram elaborados pelos próprios professores do Colégio Pedro II, algo bem diverso da proposta comeniana de transformar o professor em especialista na "arte" de executar o manual. Conforme Alves \& Centeno (2009, p. 482-483), a função desses compêndios ainda se encontrava distante daquelas atribuídas ao manual didático por Comenius. Havia, ainda, uma identificação do autor com o seu trabalho. Essa situação se explica pelo fato de a educação escolar ainda não ter atingido a todos, processo esse só iniciado a partir de década de 1930.

Atendendo a uma clientela restrita, composta por filhos dos grandes proprietários rurais, de comerciantes e das nascentes, mas minguadas camadas médias urbanas, ao ensino secundário não se impôs a força de 
uma pedagogia imbuída dos recursos necessários para "ensinar tudo a todos". Mal se insinuava a determinação material que avassalaria, na sequiência, a incipiente divisão do trabalho didático existente, os instrumentos de trabalho e os procedimentos do professor, bem como, por decorrência, a relação educativa, cujas características e práticas ainda atreladas Às pedagogias da época colonial, pouco se conformavam às formas mais desenvolvidas da escola moderna (ALVES \& CENTENO, 2009, p. 486).

\section{O "Projeto Araribá História"}

Projeto Araribá é o nome dado à coletânea de livros didáticos da Editora Moderna, a fim de atender aos anos finais do ensino fundamental, $6^{\circ}$ a $9^{\circ}$ ano, nas disciplinas de Ciências, Geografia, História, Matemática e Português. Segundo a Editora Moderna a coletânea pretende "contribuir com a melhoria da qualidade do ensino" dispondo de "princípios claros, compartilhados pelos membros da comunidade educativa, que guiam as ações para atingir os melhores resultados" (EDITORA MODERNA, 2009). Conforme ainda a Editora Moderna são três os princípios da coleção: 1) Programas específicos em cada disciplina para desenvolver a competência leitora; 2) Programa de atividades, com propostas variadas e em nível crescente de complexidade e 3) Organização clara (EDITORA MODERNA, 2009).

O manual da área de História, o Projeto Araribá História, segue um dos "princípios" desta coleção, ao propor a compreensão leitora, denominada também de competência leitura, norteadora e apontada como um dos objetivos centrais (PROJETO ARARIBÁ, 2007, p. 10). Por "compreensão" entende-se a "capacidade de apropriar-se do conhecimento e aplicá-lo em situações relativamente novas" (PROJETO ARARIBÁ, 2007, p. 10). A leitura é concebida como

[...] forma de relação com o mundo pela construção de significados [...] aprender a ler um texto é aprender a ler o mundo, processo hermenêutico no decorrer do qual o educando se apropria de significados e cria um repertório que lhe permitirá interagir critica e autonomamente com o mundo que o cerca (PROJETO ARARIBÁ, 2007, p. 10).

Considerações acerca da "competência leitura" irão ser tecidas ao final do artigo.

O Projeto Araribá História não faz indicação clara de autoria. Na folha de rosto encontra-se a informação de que se trata de uma "obra coletiva, concebida, desenvolvida e produzida" pela Editora Moderna. Aponta como editora responsável Maria Raquel Apolinário Melani, professora da rede estadual e municipal de ensino, bacharel e licenciada em História pela USP. No verso da folha de rosto, dentre inúmeras informações, apresenta uma lista diminuta sob o título Elaboração de Originais, onde relaciona cinco nomes que, à exceção de um, são apontados como editores (as). Três deles são professores, quatro possuem apenas graduação e um é mestrando4. Das observações apontadas, deduzimos preliminarmente: 1) a falta interesse por parte da editora em divulgar os nomes dos autores; 2) os profissionais elencados, em sua maioria, têm apenas graduação de nível superior e atuam na educação básica; 3) a intenção de aglutinar vários autores num mesmo projeto.

Décio Gatti Junior (2004), em sua pesquisa sobre manuais didáticos escritos e publicados entre as décadas de 1970 e 1990, apontou uma tendência um pouco diversa em 
relação à formação dos autores de manuais. Os autores por ele entrevistados tiveram formação acadêmica mais avançada, como especialização, mestrado e doutorado, situação distinta dos autores do manual aqui analisado. Porém, discutiu um dado que se aproxima de nossas observações, referente à tendência em simplificar ou especializar o trabalho do autor. Esse dado demonstra que o autor de manual didático está perdendo cada vez mais autonomia na sua atividade, o que elimina, gradativamente, a identificação subjetiva com tal instrumento de trabalho. Nas entrevistas realizadas com editores da Editora Lê e Saraiva, a respeito das relações estabelecidas entre estes e os autores, evidencia-se uma clara demonstração de que o autor é visto como um parceiro, ou seja, ele apenas "participa" do produto (FACCIOLLI; FRUET, apud GATTI JUNIOR, 2004). Os editores apontam, também, a preferência por mais de um autor na produção de um manual e que o mesmo esteja "intimamente ligado com a sala de aula" (GATTI JUNIOR, 2004, 188-189). Essas tendências são interpretadas por Gatti Junior como necessidades ligadas:

à capacidade de os autores estarem modernizando suas coleções constantemente, mantendo-se sempre afinados com a linguagem dos alunos; a disponibilidade dos autores para realizarem essas modernizações, lançando coleções novas em ritmo veloz, e sobretudo, participando das fortes estratégias de divulgação da editora (GATTI JUNIOR, 2004, p. 190)

\subsection{Organização didática do Projeto Araribá História}

Como foi anunciado anteriormente, foi escolhida uma temática, a Guerra da Tríplice Aliança, e, por essa razão, a análise centrou-se no manual destinado à $7^{\mathrm{a}}$. série que, na atual organização escolar, transformou-se em $8^{\circ}$. ano.

Os conteúdos do manual reservados à sétima série estão distribuídos em oito unidades. As unidades subdividem-se em duas partes principais: as páginas denominadas Estudo dos temas, local em que se desenvolve o conteúdo da unidade e as páginas reservadas para uma seção intitulada Em foco, local reservado para ampliar os conteúdos da unidade.

As páginas de Estudo dos Temas vêem acompanhadas de atividades de dois tipos

[...] voltadas para a construção de um relato e atividades de ampliação do conhecimento. As primeiras estão organizadas em três categorias básicas: Organize o conhecimento, Explique e Na linha do tempo. As últimas podem ser de sete tipos: Personagem, Ontem e Hoje, Edifícios daquele tempo, Mapas históricos, Arte e história, Ciência e tecnologia e Conceitos históricos. (GUIA, PROJETO ARARIBÁ, 2007, p. 9).

Nas colunas laterais do livro localizam-se três tipos de "boxes", que recebem as seguintes denominações: 1) Complementação de informações do texto, composto por pequenos textos; 2) Glossário, com os significados de termos "menos conhecidos" e 3) Problema, criado para caracterizar "polêmicas que dividem os historiadores" (PROJETO ARARIBÁ, 2007, p. 8).

A segunda parte, Em Foco, reúne textos que, segundo o manual, são "uma espécie de monografia em que você [aluno] vai estudar com mais detalhes um tema relevante para o estudo da unidade" (PROJETO ARARIBÁ 2007, p.9). Essa parte também conta com atividades que "visam desenvolver a (...) capacidade de observar e investigar as fontes históricas, além de estimulá-lo [aluno] a formar opiniões sobre questões polêmicas" (PROJETO ARARIBÁ 2007, p. 8). A referida parte, Em Foco, ainda envolve uma seção denominada Compreender um texto. Esta seção "traz diferentes tipos de textos (literários, artigos jornalísticos e de historiadores, documentos oficiais), que (...) estimulam [o aluno] a gostar de ler e a compreender as leituras que faz" (PROJETO ARARIBÁ, 2007, p. 9) 
No livro do professor encontram-se orientações detalhadas acerca do uso do manual. Essas orientações estão disponibilizadas numa seção intitulada Guia e recursos Didáticos. Lá são expostos objetivos, pressupostos, indicações de leituras e orientações específicas sobre todos os passos do trabalho didático com o manual. Esse guia se estrutura em seis tópicos:

1) Apresentação da Unidade, com "um esquema da unidade do livro comentando a importância do tema e explicitando os objetivos centrais" (PROJETO ARARIBÁ, 2007, p. $16)$;

2) Desenvolvimento didático, onde se ministram "orientações para o trabalho com as questões de abertura da unidade e [...] sugestões de desenvolvimento para as páginas de Estudo dos temas, Em foco e Compreender um texto. O item Temas para reflexão sugere algumas discussões possíveis em sala de aula" (PROJETO ARARIBÁ,1997, p. 16);

3) Ampliação, local onde se apresentam

temas que podem ser desenvolvidos em sala de aula. Eles são introduzidos por um pequeno 'olho' que apresenta o conteúdo e o seu significado para o contexto da época. Os textos desta seção são adequados aos alunos e podem ser reproduzidos para o trabalho em sala (PROJETO ARARIBÁ, 1997, p. 16);

4) Leitura complementar onde se seleciona(m)

uma ou duas leituras, de autores consagrados e relacionados aos conteúdos da unidade, oferecendo ao professor reflexões teóricas que visam ampliar o seu repertório de textos sobre o assunto e auxiliá-lo no trabalho em sala de aula ( PROJETO ARARIBÁ, 1997, p. 17);

5) Sugestões de atividades "de acordo com os objetivos essenciais traçados na coleção e os específicos de cada unidade" (PROJETO ARARIBÁ, 1997, p. 17) e

6) Sugestões de leituras, filmes e sites, que comportam "indicações de leituras que contribuem para a formação dos professores e dos alunos, além de recursos complementares no trabalho com cada tema". (PROJETO ARARIBÁ, 1997, p. 17).

O Guia é encerrado com as respostas de todas as atividades propostas no manual.

\section{A Guerra da Tríplice Aliança}

A Guerra da Tríplice Aliança é tratada no interior da Unidade oito, intitulada Brasil: da Regência ao Segundo Reinado.

Esse conflito foi um dos maiores e mais marcantes ocorridos no hemisfério sul da América, envolvendo quatro países da região platina: Paraguai, Brasil, Argentina e Uruguai. Ocasionou intensa migração de paraguaios para o sul do estado de Mato Grosso, fato que gerou significativa troca cultural entre os imigrantes e brasileiros. No plano da interpretação, o conflito ocasionou controvérsias históricas entre os países envolvidos.

Embora se reconheça no meio acadêmico a existência de três interpretações históricas sobre a Guerra, consideramos apenas duas as tendências historiográficas. Em estudo sobre manuais didáticos do século XIX, concluímos que

No Brasil, essa historiografia pode ser enquadrada em duas tendências ao longo do tempo, a seguir caracterizadas resumidamente. A primeira, hegemonizada pela interpretação dos historiadores militares, foi dominante até a década de 1960. Circunscrita, de início, às memórias dos combatentes e aos relatórios de campanha dos oficiais, em seguida assistiu ao despontar das obras de síntese de historiadores militares como Tasso Fragoso (1956-1960, 5 v.). A segunda tendência emergiu no final da década de 1960, envolvendo estudiosos argentinos, uruguaios e brasileiros, como Leon Pomer (1980), Vivian Trias (1975), Eduardo Galeano (1978) e Júlio Chiavenato (s.d.). Teve a virtude de mostrar o 
lado universal de um conflito até então visto como de âmbito local, ao destacar suas determinações econômicas gerais atadas à dinâmica da sociedade capitalista, no século XIX, e à mediação política exercida pela Inglaterra, a potência econômica mais avançada à época. Alguns consideram ter sido inaugurada uma terceira tendência, configurada em estudos recentes que pretendem construir uma "nova história da guerra". Nascentes na passagem da década de 1980 para a de 1990, dentre eles ganharam realce o de Francisco Doratioto (2002). A pretexto de corrigir os desacertos explicativos da tendência anterior, decorrentes do nacionalismo e da teoria da dependência, o que é certo, parece que essa tendência, justificando-se na necessidade de renovar os estudos historiográficos, acabou por recolocar em primeiro plano as velhas querelas locais para explicar o conflito, circunscrevendo suas análises, sobretudo, à instância política. Nesse aspecto, se aproxima da versão produzida pela história militar, a despeito de seu discurso mais acadêmico. (ALVES \& CENTENO, 2009, p. 475) página.

Apesar de sua importância a temática referida é desenvolvida em apenas uma

Quanto à versão veiculada, verificamos que os autores são ecléticos, à medida que incorporam dois tipos de interpretação histórica. Há trechos, por exemplo, que afirmam ter o conflito se originado de uma disputa localizada na região do Prata. Ou seja, para o manual o conflito platino foi gerado pela intromissão do Brasil e da Argentina nos assuntos "internos do Uruguai, cujo poder era disputado por duas facções políticas: O Partido Blanco e o Partido Colorado" (PROJETO ARARIBÁ, 2007, p. 195). Tentando explicar com maior clareza os apoios recebidos por essas facções, o manual incorre numa visível ambigüidade: "o Brasil apoiava os colorados; a Argentina se punha sobretudo ao lado dos blancos, mas também era a favor dos colorados". (PROJETO ARARIBÁ, 2007, p. 195).

Outra interpretação sugere a interferência da Inglaterra no conflito ao afirmar que, após a guerra, esse país teria se beneficiado da abertura do mercado paraguaio aos seus produtos.

Quando o conflito acabou, o Paraguai teve boa parte de suas terras anexada pelos vencedores, além de arcar com uma pesada dívida de guerra. Sua população foi reduzida a um quinto e ficou com uma maioria de mulheres, idosos, inválidos e crianças. As indústrias ruíram, o latifúndio voltou, e o mercado paraguaio foi invadido pelos produtos ingleses. Com isso, a prosperidade do Paraguai deu lugar a um dos maiores subdesenvolvimentos da América Latina (PROJETO ARARIBÁ, 2007, p. 195)

Sintetizando, quanto às idéias veiculadas acerca dessa temática, observamos que o manual incorpora duas tendências historiográficas incompatíveis. Uma delas é a de que a Guerra teria se originado por conflitos locais. A outra, afirma que esse conflito foi gerado por interesses ingleses na região.

Além do conteúdo descrito, é disponibilizado o "boxe" Um Problema para discutir divergências nas interpretações sobre a guerra. Como já foi explicitado, tal "boxe" foi criado para focalizar "polêmicas que dividem os historiadores", a fim de demonstrar "que não existe uma verdade absoluta sobre os acontecimentos estudados" (PROJETO ARARIBÁ, 2007, p. 8). A polêmica, como se observa na seqüência, é exposta de forma bem simplificada. De fato, são apontadas três versões sobre a Guerra, mas não são demonstradas as suas origens, o que as motivava, nem são citados os principais historiadores nelas enquadrados. 
A Guerra do Paraguai, durante algum tempo foi vista pelos historiadores como uma forma de combater o ditador Solano Lopez e seus planos expansionistas. Nas décadas de 1960 e 1970, outros historiadores deram ênfase aos interesses da Inglaterra na região do Rio da Prata como principais fatores para o conflito. Por essa visão, o crescimento econômico paraguaio desagradaria aos ingleses, que agiram para desarticulá-lo, mantendo assim o controle econômico sobre a região. As correntes historiográficas mais recentes não negam a influência inglesa, mas destacam as disputas e os conflitos regionais que envolviam a posse de áreas contíguas aos rios Uruguai e Paraguai. (PROJETO ARARIBÁ, 2007, p. 195).

Além do boxe, é exposto um pequeno mapa. Retirado do Atlas histórico escolar, Rio de Janeiro, FAE, 1991, tem como título Países da Bacia do Prata e destaca a região do conflito e os territórios anexados à Argentina e ao Brasil após a Guerra. O mais curioso é que no caso do território anexado pela Argentina, a legenda informa: "território paraguaio anexado pela Argentina”. Quanto ao território anexado pelo Brasil, a legenda usa uma ênfase diferente para realizar um exercício de conciliação política: "território brasileiro pretendido pelo Paraguai” (PROJETO ARARIBÁ, 2007, p. 195).

Nada mais é mencionado sobre a Guerra, com exceção de uma atividade e de indicações de fontes em Sugestões de leitura, filmes e sites, no Guia e Recursos Didáticos de uso exclusivo do professor. A atividade solicita a observação de uma pintura que retrata uma mulher ao redor de escombros de guerra. Aparenta tristeza, está cabisbaixa, porta trajes simples e encontra-se descalça. Por meio da observação dessa imagem pretende-se que o aluno possa responder às seguintes questões: a) que países participaram do conflito? b) qual a razão principal que levou à guerra? c) que conseqüências a guerra trouxe para o Brasil e para o Paraguai? d) que impressão o pintor paraguaio nos transmite sobre a guerra? Segundo as informações do manual, a tela é datada de 1880 e tem como autor o pintor "paraguaio" Juan Manuel Blanes. Contudo, segundo o Museo Nacional de Artes Visuales de Montevidéu, a tela é de 1879 e o autor é de nacionalidade uruguaia (MUSEO...,2009).

Ora, segundo o Projeto Araribá História, a incorporação de uma imagem de época tem como intuito enriquecer o conhecimento do aluno com o uso de fontes primárias, colocando a prática da análise de fontes como um dos principais eixos da proposta. Mas, nesse caso, ao repassar uma informação incorreta, o manual demonstra um descuido com a abordagem das fontes e não cumpre com o objetivo proposto.

Além disso, com exceção da última pergunta, que ligação existe entre o que foi questionado e a imagem? Uma pintura não é efetivamente um registro automático de uma cena e sim algo construído segundo a imaginação do artista e comporta interpretações subjetivas. É uma produção que merece análise sobre símbolos, categorias estéticas, dentre outras.

Quanto à indicação de leituras encontrada no Guia e Recursos Didáticos, dentre as fontes bibliográficas relacionadas sobre a unidade, encontramos a obra de Julio José Chiavenatto, Genocídio americano, indicada para os alunos, e a de Leon Pomer, Guerra do Paraguai: a grande tragédia rio-platense, recomendada para o professor. Há também a indicação do filme Guerra do Brasil, dirigido por Sylvio Back. A sugestão de leituras demonstra que os autores elegem apenas a interpretação econômica da Guerra. Isso indica que o objetivo de demonstrar "que não existe uma verdade absoluta sobre os acontecimentos estudados", norteador do boxe Um Problema, acaba se tornando inócuo, pois não basta afirmar "num boxe" que existem versões sobre um fato histórico. É necessário demonstrá-las e discutir suas razões por meio de suas fontes. O filme, de certa forma, abre mais reflexões sobre as duas versões, mas é importante ressaltar que as fontes 
relacionadas para o professor e para aluno são sugestões que aparecem apenas no Guia e recursos didáticos destinado ao professor e não há garantia de que sejam incorporadas ao trabalho didático de forma sistemática.

\section{Organização do trabalho didático}

Do ponto de vista do trabalho didático, o manual procura simplificar as operações realizadas pelo professor. É extremamente detalhado e tenta cobrir todas as etapas do trabalho de ensino.

Como foi demonstrado anteriormente, o manual é constituído por: 1) uma Página de abertura, 2) uma parte denominada Estudo do Tema e 3) uma parte denominada Em foco.

A Página de abertura segundo o Guia e recursos didáticos, deve trazer uma imagem ou ilustrações representativas do conteúdo central da unidade. Tem como função orientar o professor sobre como motivar o aluno ao iniciar uma unidade (PROJETO ARARIBÁ, GUIA E RECURSOS DIDÁTICOS, 2007, p. 9). O texto de abertura, ainda segundo o guia, deve ser "motivador", de forma a possibilitar o estabelecimento de relações entre o tema e algumas questões da atualidade. São apresentadas, também, duas atividades orais denominadas $\mathbf{O}$ que você sabe? e Questões. A primeira realiza uma sondagem sobre o conhecimento prévio do aluno e, a segunda, deve ser desenvolvida ao final da leitura unidade para aferir as respostas dos alunos. Tais questões são "consideradas centrais para o entendimento de cada tema", (id.ibid, p. 9).

Seis imagens fazem a abertura da página retratando: 1) a Guerra dos Farrapos; 2) o Corpo de Cavalaria da Guarda Nacional; 3) o desembarque de escravos num porto brasileiro; 4) imigrantes trabalhando numa colheita de café; 5) o trabalho escravo na moenda de café e 6) aclamação de D. Pedro II.

As perguntas dessa página introdutória, recomendadas para realizar a sondagem inicial do conhecimento do aluno sobre o assunto, estão associadas às imagens e realizam as seguintes interrogações:

\footnotetext{
- Como a imagem 1 representa os farroupilhas?

- Que contrastes você observa ao comparar as imagens 1 e 2?

- Que situação está representada na imagem 3?

- Ponha as imagens 4, 5 e 6 em ordem cronológica.
}

Ainda que essa atividade oral tenha sido proposta apenas como sondagem, é possível prever que os alunos terão dificuldade de relacionar as imagens com os acontecimentos históricos pois, estes, nem mesmo foram discutidos pelo manual.

As questões que o aluno deve responder ao final do estudo da Unidade são:

- Cite duas razões que explicam o grande número de revoltas que houve durante o período regencial.

- Relacione a expansão cafeeira com o desenvolvimento das ferrovias no Centro-sul do Brasil.

- Explique por que o fim do tráfico negreiro trouxe dificuldades para a lavoura cafeeira e indique as saídas encontradas para solucionar o problema.

Como se observa, o aluno deve terminar a unidade revelando as "competências" para: 1) expor duas razões sobre o número de revoltas ao longo do período regencial, 2) fazer relação do desenvolvimento das ferrovias com a expansão do café e 3) explicar as dificuldades que o fim do tráfico negreiro teria trazido para a lavoura de café e as formas de superação pensadas para o impasse.

O texto de "motivação" da Página de abertura aborda o café, o "nosso principal produto agrícola de exportação". O texto discute, em poucas linhas, a importância do café na atualidade e afirma que sua introdução ocorreu no século "XVIII". Com orgulho, alega 
que, no "inicio do século seguinte" [século XIX], o país era o principal produtor mundial. Como se vê, o texto ora apelando para a atualidade, ora ao século XVIII, ora ao XIX, demonstra ser bastante impreciso com relação à temporalidade, pois não aponta com objetividade a época tratada pela referida unidade. O aluno não consegue focar o período em referência e acaba ficando sem noção do processo histórico.

Mais curioso e inusitado ainda é o fato de o texto motivador da Página de Abertura não dar a menor importância ao tema que dá título à unidade Brasil: da Regência ao Segundo Reinado. É impossível compreender por que esse título foi atribuído à Unidade. Além disso, são pleiteadas categorias imprecisas para objetivar as mudanças do período. Por isso, do ponto de vista lógico, a conclusão é paradoxal, pois as mudanças não geraram mudanças.

Apesar das mudanças, as bases do Brasil não se modificaram. Ele continuou sendo um país agrário, exportador de matérias-primas agrícolas e politicamente comandado pelos grandes proprietários rurais" (PROJETO ARARIBÁ, 2007, p. 186).

As orientações sobre essa parte do manual são descritas passo a passo no guia do professor.

[...] sugerimos iniciar a atividade perguntando aos alunos o que sabem do período. As respostas devem ser anotadas no quadro. A partir disso, pedir-lhes que vejam as imagens e leiam as legendas, completando as informações do quadro. Ao final, pedir a eles que realizem as quatro atividades sugeridas na seção (PROJETO ARARIBÁ, GUIA E RECURSOS DIDÁTICOS, 2007, p. 80)

Para simplificar as atividades realizadas pelo professor, o guia também comporta as respostas das "Questões" da página de abertura.

Após a abertura da unidade propõe-se a leitura das páginas de Estudo dos temas. Estas procuram realizar a "apresentação clara e simples dos fatos e conceitos fundamentais", evitando a apresentação de "um volume excessivo de informações, que penalizam a compreensão leitora e levam à dispersão" (PROJETO ARARIBÁ, GUIA E RECURSOS DIDÁTICOS, 2007, p. 9). Para atender a "compreensão leitora" ou "competência leitura" são resumidas as lições em temáticas e organizadas as informações em "parágrafos e blocos de textos não muito longos que tendem a se estender no decorrer do trabalho com os livros da coleção" (ID. IBID, p. 9).

A competência aparece novamente, com ênfase, no conjunto das atividades prescritas pelo manual. No interior do desenvolvimento temático, o manual propõe atividades que visam atender "a um dos objetivos centrais da coleção, que é desenvolver a competência leitura" (ID.IBID., p. 10). Para tanto, explica de que maneira as atividades podem ajudar a cumprir o referido objetivo. Aquelas atividades voltadas para a construção de um relato

partem, em geral, de questões mais simples (Organize o conhecimento), em que os alunos vão retomar o conteúdo estudado e elaborar fichas, montar quadros comparativos e esquemas. No momento seguinte, com as atividades da Atividade Explique, eles são solicitados a realizar tarefas mais complexas, como analisar e interpretar textos e imagens, elaborar pequenos textos, criar gráficos e esquemas, comparar diferentes tipos de fontes e formular hipóteses. Na seção Explique, portanto, os alunos vão aplicar os conhecimentos trabalhados na unidade em situações relativamente novas. As atividades de ampliação de conhecimento estão relacionadas aos novos conteúdos introduzidos, por exemplo, na seção Personagem, Arte e história ou Ontem e hoje. Cada assunto escolhido explora um ponto particular da história, sempre relacionado com os conteúdos anteriormente visto, que não foi desenvolvido no texto 
didático. O objetivo é ampliar a percepção do aluno em relação à produção histórica do ser humano, mostrando-lhe as várias fronteiras que o saber histórico pode explorar. As questões propostas nessas seções desenvolvem habilidades semelhantes às trabalhadas anteriormente, mas estão centradas na compreensão dos novos conhecimentos trazidos pelos textos. Além dessas, há as atividades de Debate na História, que possibilitam ocasiões de discussão e interatividade, e as de Pesquise, que contribuem para desenvolver o método da investigação. (PROJETO ARARIBÁ, GUIA E RECURSOS DIDÁTICOS, 2007, p.10).

De fato, os tipos de atividades propostas foram pensados para atender aos pressupostos das chamadas "competências". A "competência leitura" não é a única referida no Guia. Outras competências são elencadas, como as de nível básico, operacional e global, previstas para serem adquiridas pelos alunos por meio das atividades prescritas no manual.

Essa parte denominada Estudo dos Temas também vem comentada no Guia do professor com orientações sobre como o docente deve conduzir a aula focando os temas mais importantes para o estudo.

A segunda parte, Em Foco, segundo o manual, é "uma espécie de monografia" proposta para que o aluno estude com mais detalhes um tema relacionado com a unidade (PROJETO ARARIBÁ 2007, p.9). Também conta com atividades que "visam desenvolver a sua capacidade de observar e investigar as fontes históricas, além de estimulá-lo a formar opiniões sobre questões polêmicas" (PROJETO ARARIBÁ 2007, p. 8). Esta parte ainda abrange uma seção denominada Compreender um texto, criada "especialmente para contribuir com a tarefa de exercitar a competência leitora" por meio de "diferentes tipos de textos (literários, artigos jornalísticos e de historiadores, documentos oficiais)" (IDEM, 2007, p. 9). Na referida unidade, essa seção, traz uma discussão sobre A questão agrária no Brasil, motivada por dois blocos de textos elaborados pelos autores do manual, fotos, além de dois extratos de documentos.

O primeiro bloco de textos aborda o século XIX discutindo a Lei de Terras no Brasil, datada de 1850, e a Lei de Terras nos Estados Unidos, datada de 1862. O objetivo é comparar as duas formas de ocupação. O segundo bloco enfoca a época contemporânea, sob os seguintes títulos: A concentração de terras no Brasil, De quem é a terra? As terras indígenas e A terra na Constituição de 1988. Os textos dos dois blocos, como foi dito,são elaborados pelos autores do manual.

Como fontes, a seção $\mathbf{E m}$ foco traz um fragmento de texto com uma definição do que é "grilagem", retirado do site do INCRA, três fotografias e trechos do Programa de Reforma Agrária do MST e de Os principais objetivos da UDR. Os dois últimos fazem parte da seção Compreender um texto, criada, como foi observado, "especialmente para contribuir com a tarefa de exercitar a competência leitora" (PROJETO ARARIBÁ, GUIA E RECURSOS DIDÁTICOS, 2007, p.12).

Embora seja uma iniciativa importante trazer fontes que vão além do conteúdo restrito do manual, observamos que estas não são suficientes para resolver a limitação, pois predomina, no caso, o texto dos autores.

Além disso, as fontes incorporadas são fotografias e fragmentos de textos e não têm o peso de uma leitura mais consistente, isto é, não ajudam a adquirir a "competência leitora".

Também a preocupação demasiada em discutir o presente acabou levando a uma simplificação da questão de terras no Brasil, por que, de fato, não cobriu o processo que se estendeu desde o século XIX até o momento atual. É muito genérica e pouco explicativa, por exemplo, a afirmação de que "A estrutura fundiária do Brasil atual, herdada da Lei de 
1850, caracterizou-se pela elevada concentração de terras" (PROJETO ARARIBÁ, 2007, p. 212). O manual não abordou de forma sistemática o conjunto dos acontecimentos que se encadearam entre o século XIX e o presente, daí as lacunas e a falta de foco no que diz respeito ao processo histórico.

A parte Em Foco também é abordada no Guia do Professor, onde são detalhadas orientações sobre como explorar cada "fonte".

\section{Conclusão}

Esse estudo se propôs a analisar o manual de História adotado na rede pública de Campo Grande, no ano de 2008: o Projeto Araribá História. Para tanto, foi escolhida a temática A Guerra da Tríplice Aliança. Como foi verificado, o Projeto Araribá História foi o manual que mais teve aceitação entre os professores das séries finais do ensino fundamental, obtendo no Guia de Livros Didáticos do MEC nota máxima em oito dos dez quesitos avaliados.

Para analisar esse manual, recorremos à abordagem histórica que busca entender esse objeto no interior de uma teia de relações sociais e, por isso, não vê o manual didático apenas como coisa. Propôs-se apresentar os fundamentos que regem a utilização desse instrumento a fim de entendê-lo como produto das relações sociais mais amplas. Dessa forma, foram buscadas referências em Comenius, educador que concebeu a escola moderna de forma mais acabada. Ao propor uma nova organização da escola, Comenius não viu outra forma de viabilizá-la sem que se utilizassem os recursos da divisão do trabalho, na forma manufatureira. Ou seja, ele buscou no capitalismo as informações que orientariam a escola de seu tempo. E os objetivos que embasavam seus propósitos eram sempre utilitaristas. Resumindo, a organização proposta por Comenius para a escola é a organização possível, necessária e útil ao capitalismo.

De fato, nosso estudo centrou-se no manual didático, o instrumento de trabalho do professor da escola moderna. Entende-se que é o manual o elemento central do trabalho didático da escola de nossa época.

No Brasil, esse instrumento foi introduzido a partir de meados do século XIX, mas não dominou o processo de ensino. Os livros didáticos eram complexos e elaborados pelos próprios professores; foram incorporados em sala de aula como instrumentos auxiliares do docente. A universalização do ensino, realizada somente após os anos 1930 impôs a adoção desse instrumento que foi ficando cada vez mais simplificado. O manual comeniano, de tamanho pequeno, que apresenta as coisas sumariamente, de muitas coisas com poucas palavras, de grande utilidade com muitas imagens foi algo que se difundiu no Brasil após a universalização do ensino.

Vimos que o Projeto Araribá é uma coletânea de livros de várias áreas que incorpora como um dos seus princípios básicos a "competência leitora". Isso foi anunciado em todas as orientações desse manual de História no Guia do Professor. Para o manual, a compreensão, denominada também de competência, é a "capacidade de apropriar-se do conhecimento e aplicá-lo em situações relativamente novas".

$\mathrm{E}$ de que forma o manual promete desenvolver a competência leitura? Paradoxalmente, com a orientação comeniana de que se deve realizar a "apresentação clara e simples dos fatos e conceitos fundamentais", e evitar a apresentação de "um volume excessivo de informações, que penalizam a compreensão leitora e levam à dispersão"(PROJETO ARARIBÁ, 2007) A proposta de simplificação de se apresentar "as coisas sumariamente, ou seja, muitas coisas com poucas palavras" encontrada em Comenius, (1997, p.221) está presente no Projeto Araribá. Ora, um grande número de livros ou de informações pode distrair os espíritos (COMENIUS , 1997, p. 206). 
Outras competências são relacionadas pelo manual, observadas como "competências de vários níveis". Elas se realizam por meio das atividades dirigidas e programadas em cada unidade de estudo.

Quanto à autoria verificamos que a Editora Moderna não quis identificar seus autores se limitando a apontar secundariamente uma organizadora. Quem assume, de fato, a autoria é a Editora Moderna. Esses dados se aproximam das observações de Gatti Junior (2004) sobre a tendência em colocar o autor como um parceiro. Ou seja, é possível apontar para maior objetivação do trabalho e a eliminação da identificação subjetiva do autor com esse instrumento.

Quanto ao conteúdo referente à A Guerra da Tríplice Aliança, observou-se que foi dada pouca atenção à temática, limitando-se a discuti-la em uma página de conteúdo. Quanto à interpretação utilizada, os autores usam do ecletismo metodológico, pois incorporam duas versões incompatíveis. O manual discute as versões sobre a Guerra, mas estas são disponibilizadas fora do texto básico, num "boxe" e de forma bem superficial. Do ponto de vista formal, constataram-se ambigüidades no texto nas informações sobre o apoio da Argentina aos partidos colorado e blanco. Constatou-se também descuido com a abordagem das fontes, ao incorporar uma pintura em tela referenciada incorretamente. Verificou-se a indicação de fontes bibliográficas sobre a Guerra no Guia e recursos didáticos do Professor, mas as indicações bibliográficas incorporam apenas uma versão e não atendem a proposta de demonstrar "que não existe uma verdade absoluta sobre os acontecimentos estudados". Importante destacar que essas fontes são apenas sugeridas no guia e não há garantia de que sejam incorporadas ao trabalho didático de forma sistemática.

Do ponto de vista do trabalho didático, o manual procura simplificar as operações realizadas pelo professor. Detalha orientações precisas sobre: 1) a preparação e motivação dos alunos antes da apresentação do conteúdo; 2) o desenvolvimento do conteúdo; 3 ) o que se deve ler 4 ); a realização das atividades previstas; 5) a ampliação do conhecimento do aluno elencando as questões mais importantes; 6) a correção das atividades fornecendo o roteiro, as respostas e os esquemas.

A Página de Abertura deve, segundo o manual, motivar o aluno, mas do ponto de vista formal seus textos e estrutura são tão confusos que geram o contrário do pretendido. O texto de motivação, por exemplo, aborda o café, mas não faz nenhuma relação com o tema da Unidade. Ao buscar formas de relacionar o presente com o tema discutido não discute o processo histórico de maneira objetiva e acaba se tornando bastante impreciso com relação à temporalidade.

A parte que discute os conteúdos sob a forma de temáticas é denominada Estudo dos temas. Nela, conforme a proposta, são discutidas as lições em textos não muito longos, evitando a apresentação de muitas informações. Como é possível por meio de textos curtos e fragmentados desenvolver a "competência leitora"?

A parte Em foco tem a função de trabalhar com fontes históricas, desenvolvendo no aluno "um olhar cada vez mais examinador e crítico" (GUIA, PROJETO ARARIBÁ HISTÓRIA, 2007, p. 6). Contudo, há poucas fontes históricas nessa seção, pois predominam textos elaborados pelos próprios autores. As poucas fontes incorporadas são fotografias e fragmentos de textos e não têm o peso de uma leitura mais consistente, isto é, não ajudam a "competência leitora".

No Guia e recursos didáticos encontramos textos disponibilizados para ampliar e complementar os conteúdos - Ampliação e Leitura Complementar-, bem como sugestões de leituras e de filmes, mas esses são acessórios ao trabalho didático. São sugestões, apenas. 
De fato, estamos diante de um instrumento que tenta incorporar modismos pedagógicos, como as competências, por exemplo, mas que, de fato, exerce funções comenianas.

Em História da Idéias Pedagógicas, Dermeval Saviani (2007, p. 444) afirma que entre os anos 1970 e 1980 o professor tinha uma cabeça escolanovista, mas as condições em que atuava eram as da escola tradicional. A partir dos anos 1990 despencaram sobre o professor uma enxurrada de exigências e de propostas que recorriam às tendências de mercado, "soluções mágicas" para resolver o problema da aprendizagem. Para Gilberto Luiz Alves, esses modismos não chegaram a alterar o trabalho didático. A pedagogia das competências não acrescenta nada de significativo e nem altera o trabalho didático,

pois é ele [ projeto comeniano] que subsiste nos seus aspectos mais essenciais até nossos dias, mesmo quando seus elementos se sujeitam a ligeiros ajustes. Esses ajustes são superficiais e não afetam as características gerais da organização manufatureira do trabalho didático.

No momento, estamos debruçando-nos mais profundamente sobre o nosso tempo, momento especialmente expressivo por coincidir com o processo de efetiva universalização da escola moderna no Brasil. Essa época testemunhou, primeiro, a disseminação do ideário burguês que postulava uma escola dualista, depois a ascendência e hegemonia do escolanovismo, no final do século XIX e dois primeiros terços do século $\mathrm{XX}$, e a emergência das críticas que tomaram as formas de contestações do anarquismo, do marxismo, do reprodutivismo e de tendências pósmodernas. Nesse percurso, especialmente o discurso pedagógico burguês também recebeu reforços, seja das tendências tecnicistas, seja da teoria do capital humano.

Mas tais discursos têm pairado sobre uma escola aferrada a práticas seculares. Nela, um recurso tecnológico de base manufatureira, em grande parte concebido por Comenius, dá o tom e subordina o trabalho do professor. Mesmo em face das elogiáveis exceções, os intelectuais da educação têm travado um debate completamente dissociado do cotidiano da escola. A disputa retórica que empreendem os representantes de diferentes tendências teóricas ganha a pífia configuração de guerra de papel (ALVES, 2010, p 52)

Ora, as competências estão no plano do discurso. De fato, estamos diante de um fenômeno denominado por Alves de "império do manual didático" (ALVES, 2006, p. 231) Por meio do manual didático, o que se veicula dentro da escola é o conhecimento vulgarizado, simplificado e fragmentado, que exclui o acesso a todas as demais fontes do conhecimento culturalmente significativo.

Finalizando, verificou-se que a função do manual Projeto Araribá História segue as recomendações comenianas à medida que substitui todas as demais fontes e recursos educativos, constatado no fato de que resume as lições em textos não muito longos, orienta passo a passo o trabalho do professor, incorpora pouquíssimos documentos na seção destinada à análise de fontes históricas. As fontes alternativas que o manual indica estão no guia reservado ao professor e parecem ter uma posição secundária no processo. Por esse motivo, nele estão depositadas e sintetizadas todas as fontes necessárias, transformando-o no único instrumento adotado. 


\section{BIBLIOGRAFIA}

ABUD, Kátia. Currículos de História e políticas públicas: os programas de História do Brasil na escola secundária. In: BITTENCOURT, Circe (Org) O saber histórico na sala de aula. 2. ed. São Paulo:Contexto, 1998.

ALVES, Gilberto Luiz. A produção da escola pública contemporânea. 4. ed. Campinas: Autores Associados, 2006.

Trabalho didático e história da educação: enfoque histórico-pedagógico.

BRITO, Silvia Helena Andrade de. et. al. (org.) A organização do trabalho didático na história da educação. Campinas: Autores Associados, 2010.

ALVES, Gilberto Luiz; CENTENO, Carla Villamaina. A produção de manuais didáticos de história do Brasil: remontando ao século XIX e início do século XX. Revista Brasileira de História da Educação. Set/dez. v. 14 n. 42, 2009

COMÉNIO, João Amós. Didáctica Magna: tratado da arte universal de ensinar tudo a todos. São Paulo: Martins Fontes, 1997.

EDITORA MODERNA. Projeto Araribá. In:

http://www.moderna.com.br/didaticos/ef2/arariba/intr/ Acesso em: 10.04.2009.

GATTI JUNIOR, Décio. A escrita escolar da História: livro didático e ensino no Brasil (1970-1990). Bauru, SP: Edusc; Uberlândia,MG: Edufu, 2004.

HOLLANDA, Guy de. Programas e compêndios de história para o ensino secundário brasileiro: 1931-1956. Rio de Janeiro: INEP/Centro Brasileiro de Pesquisas Educacionais.. (Currículos, programas e métodos, 1), 1957.

MACEDO, Joaquim Manoel de. Lições de História do Brasil. Rio de Janeiro: Garnier, 1905.

MUSEO NACIONAL DE ARTES VISUALES. Juan Manuel Blanes In: http://www.mnav.gub.uy/blanes.htm. Acesso em : 30.03.2009.

PROJETO ARARIBÁ HISTÓRIA. 1. ed. São Paulo: Moderna, 2006.

SAVIANI, Dermeval. História das idéias pedagógicas no Brasil. Campinas: Autores Associados, 2007.

\footnotetext{
${ }^{1}$ Doutora em História e Filosofia da Educação-UNICAMP, professora de História e Filosofia da Educação da UEMS, Unidade de Campo Grande/MS.

${ }^{2}$ O Programa intitula-se Instrumentos do trabalho didático e relação educativa na escola moderna, desenvolvido pelo Grupo de Estudos e Pesquisas História, Sociedade e Educação no Brasil - HISTEDBR, Regional de Mato Grosso do Sul. Parte desse estudo vincula-se à pesquisa financiada pelo CNPQ.

${ }^{3}$ Segundo levantamento realizado pela acadêmica Andréia de Souza Cássio no ano de 2008, na Secretaria Municipal de Educação em Campo Grande.

${ }^{4}$ Maria Raquel Apolinari Melani bacharel e licenciada em História pela Universidade de São Paulo, professora da rede municipal e estadual de ensino, João Carlos Agostini, licenciado em História pela Universidade de São Paulo, professor da rede particular de ensino, César da Costa Júnior, bacharel e licenciado em História pela Universidade de São Paulo, professor da rede pública e particular de ensino, Maria Dolores Pérez Vasconcellos, bacharel e licenciada em História pela Pontifícia Universidade Católica de São Paulo e Silvia Carvalho Ricardo, bacharel em Administração Pública pela Escola de Administração de Empresas de São Paulo da Fundação Getúlio Vargas, mestranda em História Econômica pela Faculdade de Filosofia, Letras e Ciências Humanas da Universidade de São Paulo.
} 